\title{
Simulation of a low-voltage distribution network when arranging voltage stabilizers
}

\author{
A. Aluynov ${ }^{1, *}, O$. Vyatkina $^{1}, E$. Gracheva $^{3}$ and $S$. Bylanov ${ }^{1}$ \\ ${ }^{1}$ Vologda State University, Lenina Street 15, Vologda, 160000, Russia \\ ${ }^{2}$ Vologda Industrial Stabilizers Plant, LLC, Vologda, Russia \\ ${ }^{3}$ Kazan State Power Engineering University, Kazan, Russian Federation
}

\begin{abstract}
A computer algorithm for optimal voltage regulation using voltage stabilizers is presented. The applied voltage stabilizers are suitable for operation with radial distribution networks, taking into account various load models. The proposed algorithm makes the initial selection, installation, and adjustment of voltage stabilizers, which provide smooth voltage regulation throughout the network, using the existing algorithms, which are appropriately modified and optimized. The algorithm is fast, efficient, and reliable, which is confirmed by its practical application in distribution networks.
\end{abstract}

\section{Introduction}

The high degree of branching of low-voltage electrical networks, an excessive number of connections, and uneven loading of power lines have a significant impact on the voltage level and can lead to instability of the power system.

Voltage stabilizer is one of the most effective voltage regulation devices in distribution networks [1,2]. The correct location of voltage stabilizer has a significant impact on its operation in distribution networks. The arrangement of voltage stabilizers in distribution networks has been studied for a long time, but some considerations have not yet been discussed. The question under study is whether the type of consumer load affects the choice of installation site and technical characteristics of voltage stabilizers [3].

Voltage stabilizers have a significant impact on voltage level of low-voltage distribution networks, and, as a result, cause changes in load current, which ultimately leads to a change in electricity losses in the network. Therefore, the load model can have an impact on the location of voltage regulators and the choice of their parameters. When modelling a low voltage distribution network, all loads are divided into constant resistance, constant power, constant current, and generalized typical load $[4,5]$.

The optimal placement of voltage stabilizers should reduce voltage deviations and power losses. It is also necessary to take into account the investment cost of voltage stabilizers and network development.

This study aims to improve the accuracy of selecting of the location and the parameters of voltage stabilizers, taking into account different load models.

\section{Materials and methods}

The stabilizer location is selected based on the calculation of voltage losses in the network. The calculation is carried out based on the current state of the network to determine the actual voltage losses to the consumer at present. It is necessary to ensure the maximum symmetry of consumer load, otherwise, the power quality may be worse for consumers located before the installation site of the stabilizer.

In the case of symmetrical load, the voltage drop in the phase conductor in the line section is determined by the formula $[6,7]$ :

$$
\Delta U=\sqrt{3} I_{E} L\left(r_{0} \cos \varphi+x_{0} \sin \varphi\right)
$$

where $I_{E}$ is the estimated line current, A;

$L$ is the section length, $\mathrm{km}$;

$r_{0}$ is the specific active resistance of the phase conductor, $\mathrm{Ohm} / \mathrm{km}$;

$x_{0}$ is the specific inductive resistance of the phase conductor, $\mathrm{Ohm} / \mathrm{km}$;

$\cos \varphi$ is the active power factor;

$\sin \varphi$ is determined from $\cos \varphi$.

Power consumption in electric power systems changes when the mode parameters (frequency and voltage) change. Therefore, for calculations, it is important to know how the load power will change.

The static characteristics of voltage loads for sets of power consumers, that is, the characteristics of load nodes, are of greatest interest.

For load nodes with consumers of different types, generalized static characteristics are constructed. The mathematical model of the generalized static characteristic is selected during experimental research.

\footnotetext{
* Corresponding author: alyunov@mail.ru
} 


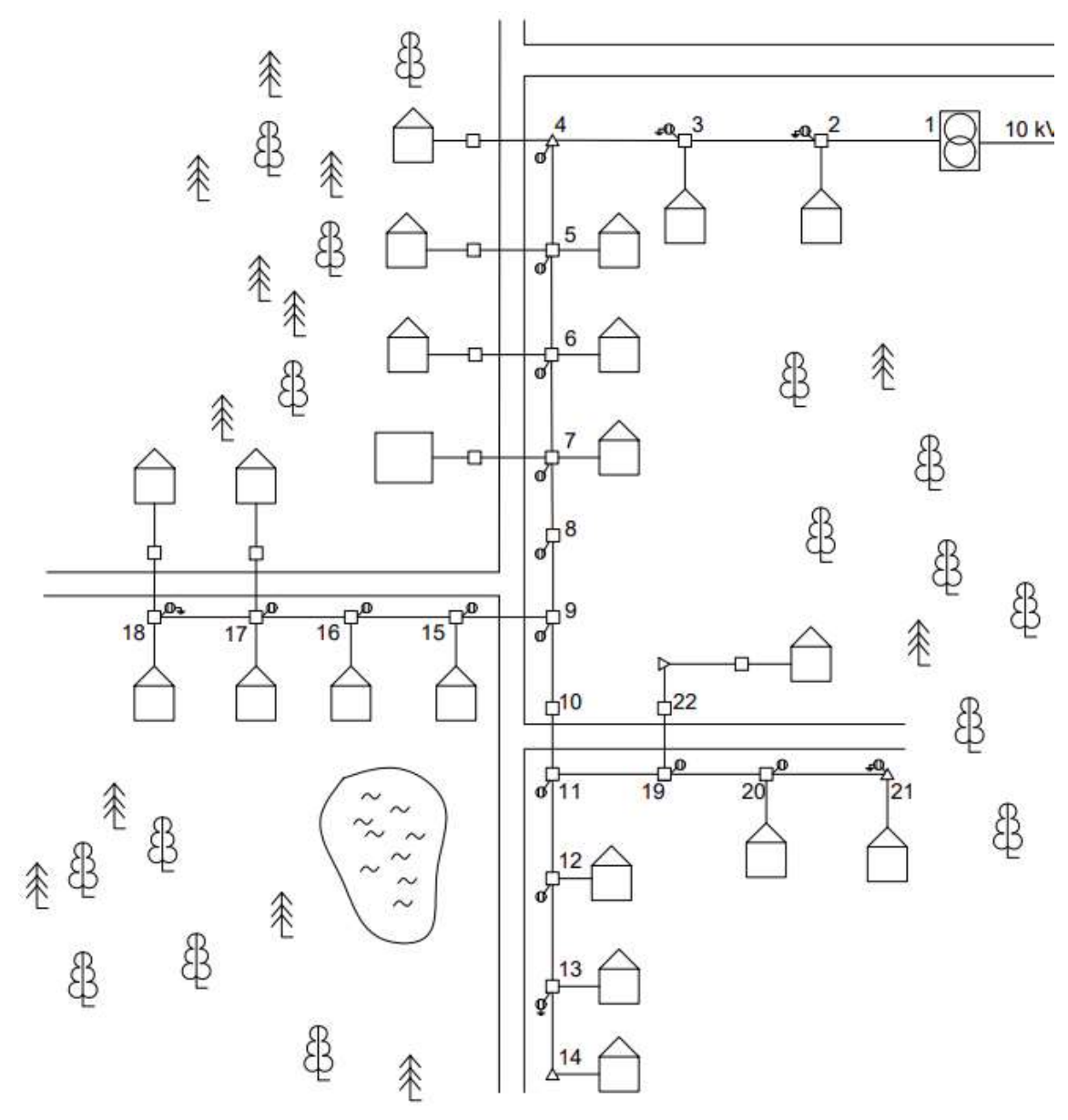

Fig. 1. The design scheme of transmission supports of a network section.

The static load characteristics are used to assess the level of load power reduction during the voltage drops on the consumer's buses. This phenomenon is called the voltage load regulation effect, which is determined by the derivatives $\frac{\partial P}{\partial V}$ and $\frac{\partial Q}{\partial V}$. The larger these values are, the more the load depends on the voltage on the consumer's buses [8,9].

The polynomial model is widely used to analyze steady-state conditions and transient processes. The model shows the relationship between the power consumption and voltage in the form of a polynomial equation that combines the components of constant resistance $(\mathrm{Z})$, current $(\mathrm{I})$, and power $(\mathrm{P})$ :

$$
\begin{aligned}
& P(V)=P_{0}\left[a_{P}+b_{P} \frac{V}{V_{R}}+c_{P}\left(\frac{V}{V}\right)^{2}\right] \\
& Q(V)=Q_{0}\left[a_{q}+b_{q} \frac{V}{V_{R}}+c_{q}\left(\frac{V}{V_{R}}\right)^{2}\right],
\end{aligned}
$$

where $P(V)$ and $Q(V)$ are active and reactive power consumed by load at voltage $V$;

$P_{0}$ and $Q_{0}$ are active and reactive power consumed by load at rated voltage $V_{R}$;

$a_{P}, b_{P}, c_{P}$ are coefficients characterizing the change in the consumed active power as a function of voltage; $a_{q}, b_{q}, c_{q}$ are coefficients characterizing the change in the consumed reactive power as a function of voltage.

\section{Results and discussions}

To carry out numerical studies, consider a $0.4 \mathrm{kV}$ lowvoltage distribution network, consisting of several sections. The design scheme of transmission supports is shown in Figure 1.

In this section, to investigate the importance of considering a load model for solving the problem of voltage regulator location, four different ways of setting the load are presented [10-12]:

- Constant resistance $(Z=$ const $)$;

- Constant power ( $\mathrm{S}=$ const);

- Direct current (I = const);

- Generalized typical load $(\mathrm{S}=\mathrm{f}(\mathrm{V}))$.

The graph of change in voltage level at the nodal points of the main line for each of the described methods of setting the load is shown in Figure 2. 


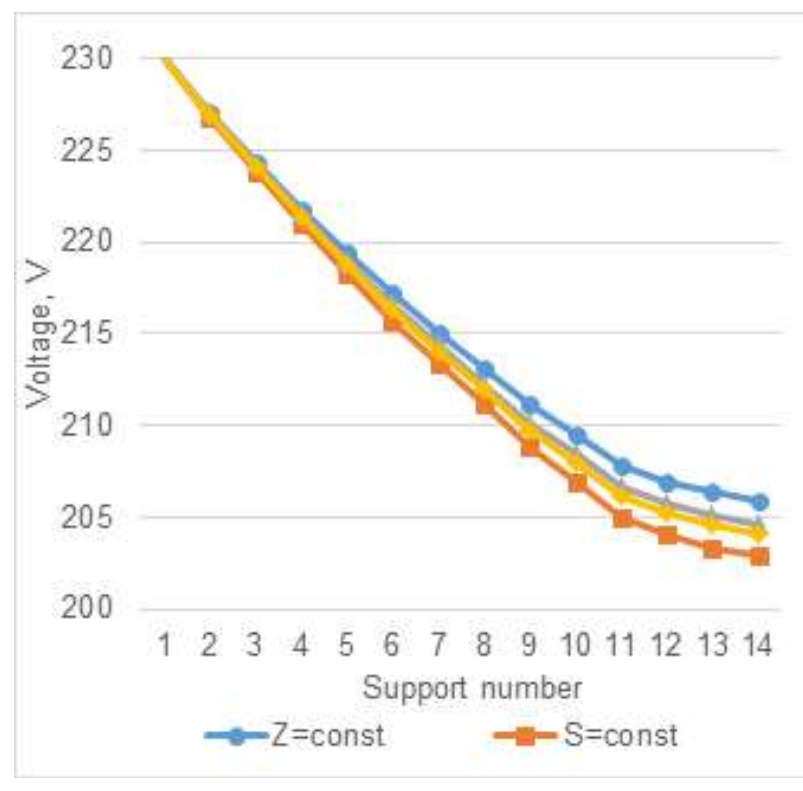

Fig. 2. The graph of change in voltage level at the nodal points of the main line.

The graph of change in voltage level at the nodal points of the main line when installing a voltage stabilizer for each of the described methods of setting the load is shown in Figure 3.

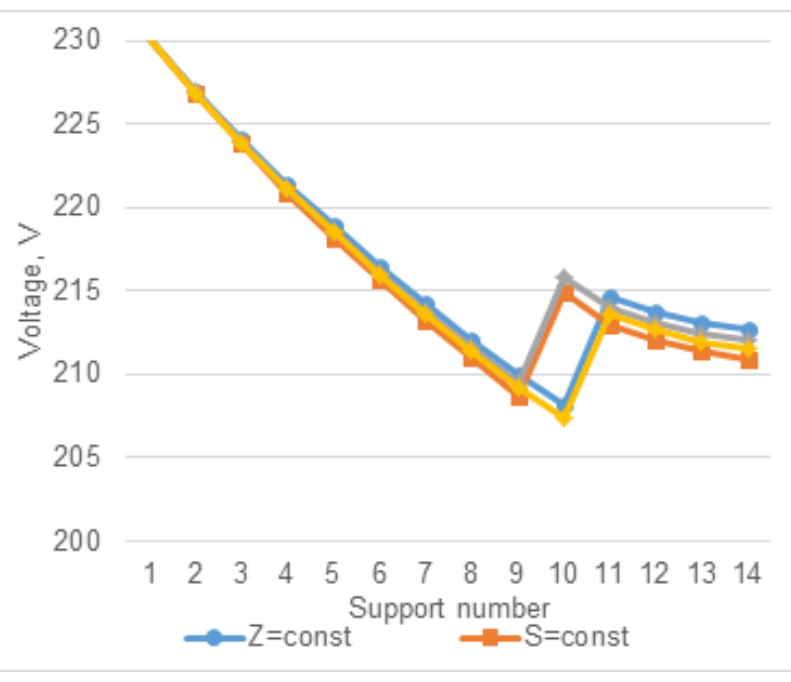

Fig. 3. The graph of change in voltage level at the nodal points of the main line when installing a voltage stabilizer.

The deviations in voltages show the influence of the method of load setting on modeling the processes in the low-voltage distribution network, on the choice of location, power and cost of the voltage stabilizer.

Figure 4 illustrates the influence of the load presentation on the increase in voltage loss when a voltage stabilizer is installed.

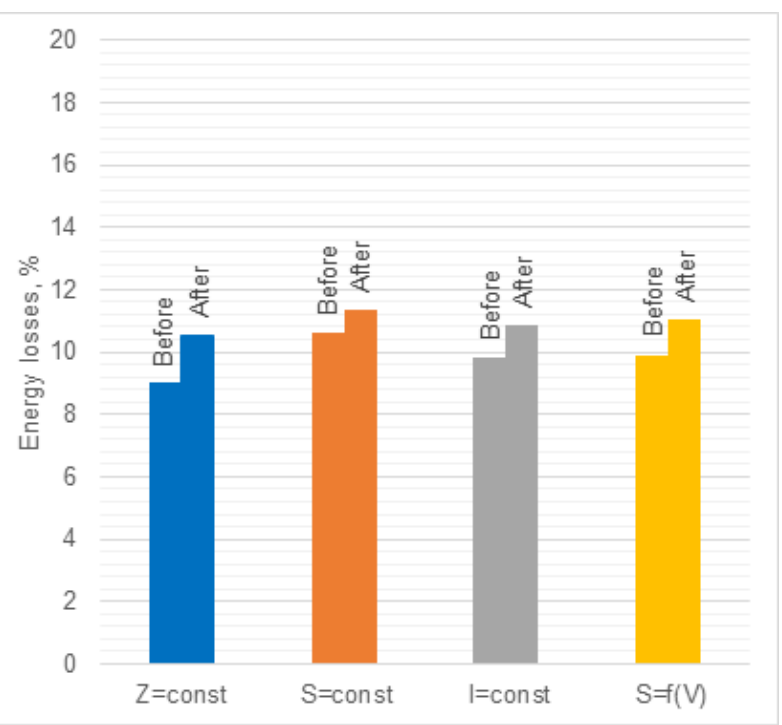

Fig. 4. Diagram of change in voltage losses when installing a voltage stabilizer for various methods of load setting.

The presented dependences show that when the load is presented as a constant resistance, the greatest increase in power losses is observed when installing a voltage stabilizer.

When the load is presented as a constant power, the smallest increase in power losses is observed when installing a voltage stabilizer.

The table illustrates the influence of the method of setting the load on the voltage stabilizer current and, as a result, on the capital investments for its purchase and installation.

Table 1. Relationship between the location and parameters of voltage stabilizers on the load model.

\begin{tabular}{|c|c|c|c|c|}
\hline The controlled & \multicolumn{4}{|c|}{ Load model } \\
\cline { 2 - 5 } parameter & $\mathbf{Z}=$ const & $\mathbf{S}=$ const & $\mathbf{I}=$ const & $\mathbf{S}=\mathbf{f}(\mathbf{V})$ \\
\hline $\begin{array}{c}\text { Number of } \\
\text { support with } \\
\text { stabilizer }\end{array}$ & 11 & 10 & 11 & 10 \\
\hline $\begin{array}{c}\text { The estimated } \\
\text { current of the } \\
\text { stabilizer, A }\end{array}$ & 116.7 & 125 & 120.2 & 121.3 \\
\hline
\end{tabular}

Thus, the optimal location of the voltage stabilizer and the choice of its capacities depend on the load model.

Taking into account the aforesaid considerations, an algorithm has been developed for choosing the optimal location for the voltage stabilizer, shown in Figure 5.

The design scheme of transmission supports of an electrical network is the initial data for the beginning of the calculation. This scheme should include the loads of consumers, the lengths and cross-sections of sections of overhead lines. Before calculating, one should set the degree of influence of consumer loads on the voltage level (static voltage characteristics). The algorithm provides the following static characteristics: constant resistance, constant power, constant current, generalized typical load.

Based on this algorithm, a computer program "Online Electric: Stabilizer" was developed in Vologda State 


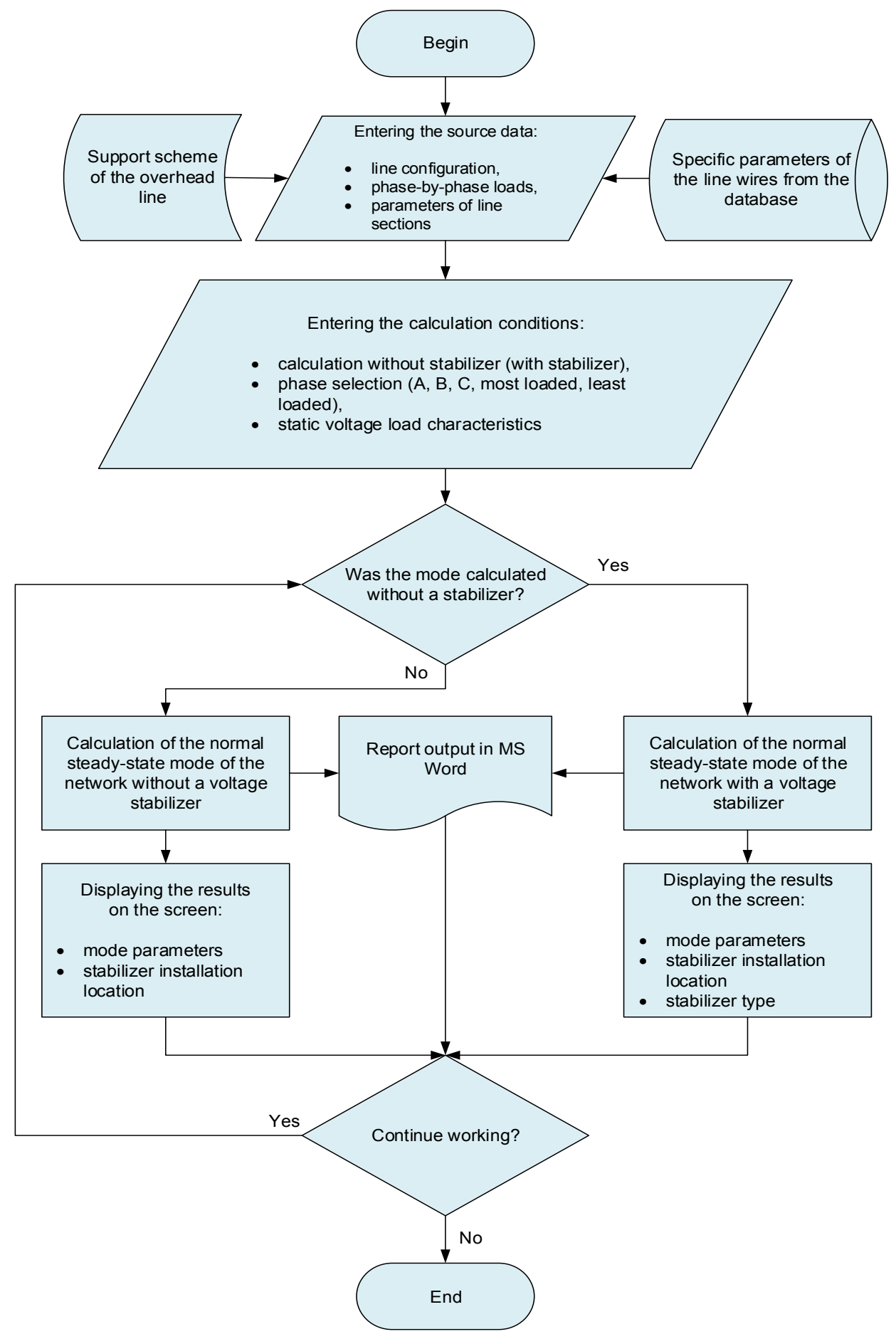

Fig. 5. Algorithm for optimal voltage regulation using a stabilizer.

University. The program is designed to select the installation sites for industrial voltage stabilizers for lowvoltage electrical networks. The developed software module is an integral part of the "Online Electric" web service. The program automatically calculates the normal steady-state mode of the electrical network, determines the circuit nodes for installing voltage stabilizers based on voltage deviations from the normalized values and calculates the mode taking into account the voltage stabilizer. As a result, it recommends a type of voltage stabilizer and the number of the support on which it should be installed.

\section{Conclusions}

The developed algorithm and computer program are used to perform modeling taking into account various methods of load setting, to calculate voltage losses based on the current state of the network, taking into account a possible decrease in consumer voltage caused by an 
increase in power consumption. The program allows one to determine the optimal location of the voltage regulator in low-voltage distribution networks. The results of the work make it possible to comprehensively assess the state of the network, improve the accuracy of determining the location of voltage stabilizers and, as a result, ensure the required level of quality of electricity for consumers.

\section{References}

1. Fallahzadeh-Abarghouei H., Nayeripour M., Hasanvand S., Waffenschmidt E. Online hierarchical and distributed method for voltage control in distribution smart grids. Generation Transmission \& Distribution IET, vol. 11, no. 5, pp. 1223-1232, 2017, doi: 10.1049/iet-gtd.2016.1096

2. Islam F.R., Prakash K., Mamun K.A., Lallu A., Pota H.R. Aromatic Network: A Novel Structure for Power Distribution System. Access IEEE, vol. 5, pp. 25236-25257, 2017 doi: 10.1109/ACCESS.2017.2767037

3. Kesici M., Yapıcı R., Güneş D., Alboyacı B., Kurtoğlu Ş. Distributed generation control to solve voltage regulation problem in distribution networks: A real case study in Turkey 2018 6th International Istanbul Smart Grids and Cities Congress and Fair (ICSG), Istanbul, Turkey, 2018, pp. 183-187, doi: 10.1109/SGCF.2018.8408969.

4. Safigianni A.S., Salis G.J. Optimum voltage regulator placement in a radial power distribution network. IEEE Transactions on Power Systems, vol. 15, no. 2, pp. 879-886, May 2000, doi: $10.1109 / 59.867188$

5. Taheri S.I., Salles M.B.C., Kagan N. A new modified TLBO algorithm for placement of AVRs in distribution system, 2019 IEEE PES Innovative Smart Grid Technologies Conference - Latin America (ISGT Latin America), Gramado, Brazil, 2019, pp. 1-6, doi: 10.1109/ISGT-LA.2019.8895471

6. Kabir M.E., Assi C., Alameddine H., Antoun J., Yan J. Demand Aware Deployment and Expansion Method for an Electric Vehicles Fast Charging Network, 2019 IEEE International Conference on Communications, Control, and Computing Technologies for Smart Grids (SmartGridComm), Beijing, China, 2019, pp. 1-7, doi: 10.1109/SmartGridComm.2019.8909746

7. Pereira G.M., Fernandes T.S.P., Aoki A.R. Allocation of Capacitors and Voltage Regulators in Three-Phase Distribution Networks. J Control Autom Electr Syst 29, 238-249 (2018). doi: 10.1007/s40313-018-0367-x

8. Attar M., Homaee O., Repo S., Rekola J. Importance Investigation of Load Models Consideration in Stand-Alone Voltage Regulators Placement in Distribution Systems, 2018 8th International Conference on Power and Energy
Systems (ICPES), Colombo, Sri Lanka, 2018, pp. 146-150, doi: 10.1109/ICPESYS.2018.8626919

9. Sajadi A., Strezoski L., Khodaei A., Loparo K., Fotuhi-Firuzabad M., Preece R., Yue M., Ding F., Levi V., Arboleya P., Terzija V. Guest Editorial: Special Issue on recent advancements in electric power system planning with high-penetration of renewable energy resources and dynamic loads, International Journal of Electrical Power \& Energy Systems, Volume 129, 2021, 106597, ISSN 01420615, doi: 10.1016/j.ijepes.2020.106597

10. Armendáriz M., Paridari K., Wallin E., Nordström L. Comparative study of optimal controller placement considering uncertainty in PV growth and distribution grid expansion, Electric Power Systems Research, Volume 155, 2018, pp 48-57, doi: 10.1016/j.epsr.2017.10.001

11. Attar M., Homaee O., Falaghi H., Siano P. A novel strategy for optimal placement of locally controlled voltage regulators in traditional distribution systems, International Journal of Electrical Power \& Energy Systems, Volume 96, 2018, pp. 11-22, ISSN 01420615, doi: 10.1016/j.ijepes.2017.09.028

12. Postigo F., Mateo C., Gómez T., de Cuadra F., Dueñas P., Elgindy T., Hodge B.M., Palmintier B., Krishnan V. Phase-selection algorithms to minimize cost and imbalance in U.S. synthetic distribution systems, International Journal of Electrical Power \& Energy Systems, Volume 120, 2020, 106042, ISSN 0142-0615, doi: 10.1016/j.ijepes.2020.106042. 